\title{
SPECIAL ISSUE ON COMPUTER CHESS ARTIFICIAL INTELLIGENCE, VOL. 43, NO. 1, APRIL 1990
}

\author{
H. J. Berliner and D. F. Beal (Eds.)
}

This special issue of Artificial Intelligence contains eight papers, of which six are reprints (sometimes amended) from papers presented at the Advances in Computer Chess 5 Conference, April 27-28, 1987, Noordwijkerhout, The Netherlands, and published before in the conference proceedings (D. F. Beal (Ed.): Advances in Computer Chess 5, Elsevier Science Publishers, Amsterdam, 1989; ISBN 0-444-87159-4; a review of this book by T. A. Marsland has appeared in the ICCA Journal, Vol. 12, No. 3, p. 169).

The following articles are included:

- $\quad$ H.J. Berliner, G. Goetsch, M.S. Campbell and C. Ebeling: "Measuring the Performance Potential of Chess Programs" (14 pages).

- $\quad$ K.-F. Lee and S. Mahajan: "The Development of a World Class Othello Program" (16 pages).

- $\quad$ H. Horacek: "Reasoning with Uncertainty in Computer Chess" (20 pages).

- $\quad$ I. Althöfer: "An Incremental Negamax Algorithm" (9 pages).

- $\quad$ J. Schaeffer: "Conspiracy Numbers" (18 pages).

- $\quad$ D.F. Beal: "A Generalised Quiescence Search Algorithm" (14 pages).

- T. Anantharaman, M.S. Campbell and F.-h. Hsu: "Singular Extensions: Adding Selectivity to Brute-Force Searching" (11 pages).

- $\quad$ S.T. Dekker, H.J. van den Herik and I.S. Herschberg: "Perfect Knowledge Revisited" (13 pages).

\section{INFORMATION FOR CONTRIBUTORS}

Contributors may be interested to know that the ICCA Journal, as of Vol. 10, No. 1, is a source for the Institute for Scientific Information ${ }^{\circledR}$ (ISI) for inclusion in the CompuMath Citation Index ${ }^{\circledR}\left(\mathrm{CMCI}^{\circledR}\right)$, the Automatic Subject Citation Alert (ASCA ${ }^{\circledR}$ ) and SCISEARCH ${ }^{\circledR}$, ISI's on-line database. The Journal is also a source for the Information Company R.R. Bowker for inclusion in the International Serials Database which is a source for Ulrich's International Periodicals Directory and the DIALOG on-line service.

Being included in the $C M C I{ }^{\circledR}$, the ICCA Journal is one of the 400 Journals in mathematics, computer science, statistics, operations research, and related disciplines which is abstracted and/or indexed and/or available as tearsheets; this means that the Journal is accessible in (on-line) database form.

\section{Submission of material}

Contributions to the Journal are welcomed in any form, although preferably by E-mail or on a MS-DOS formatted 5.25 inch diskette. In case contributors prepare their manuscripts with high-quality wordprocessors, it should be noticed that text-files in VENTURA, TEX or TROFF format are processable directly by the Editors, thereby alleviating their task considerably.

\section{ICCA's SPONSORS}

The production of the ICCA Journal depends on authors submitting their articles and on a secretarial staff, first guiding the submissions through the refereeing process and then taking care of the text down to the last detail. The latter is a heavy and time-consuming task.

The Editors and the Board of the ICCA gratefully recognize the SWOL Foundation (Foundation for Scientific Education in Limburg), who provided the Editor-in-Chief for 1990 again with a voluntary grant for part of the support required. Another part of the costs for Vol. 13, No. 2 up to Vol. 14, No. 1, both inclusive, has been contributed by IBM Nederland N.V. The ICCA gratefully acknowledges both sponsorships, but stresses that not all financial problems are solved thereby and therefore wholeheartedly invites new sponsors. 